\title{
Evaluasi Lanskap Jalan Jenderal Ahmad Yani Pontianak
}

\author{
AGUS RULIYANSYAH ${ }^{\star}$ \\ 1. Program Studi Agroteknologi, Fakultas Pertanian, Universitas Tanjungpura \\ Pontianak 1049, Indonesia \\ *E-mail: agus.ruliyansyah@faperta.untan.ac.id
}

\begin{abstract}
Streetscape Evaluation at Jenderal Ahmad Yani Street Pontianak

Jenderal Ahmad Yani Street is the main street in the city of Pontianak. Ahmad Yani street landscape must be planned in order to function properly. The purpose of this study were 1) to evaluate the function of the architectural aspect, aesthetics and maintenance and 2) provide appropriate recommendations on the management of Ahmad Yani street landscape. Survey method was used in this study by dividing Ahmad Yani street down into three segments. The results showed that the segments 2 and 3 meet the criteria of architectural aspects. Aesthetic aspects for segments 2 and 3 was considered quite meet unless segment 3 , while for the maintenance aspects of the three segments known that meet both criteria. Planting should be composed with the landscape tanama good to get a strong visual impression according to the social and environmental conditions of the landscape in each segment.
\end{abstract}

Keywords: aesthetic, Ahmad Yani street, architectural, streetscape

\section{Pendahuluan}

Kota Pontianak adalah kota jasa dan perdagangan yang berkembang pesat. Aktivitas masyarakat dalam kehidupan sehari-hari tergolong sibuk. Arus pergerakan kendaraan cukup padat sehingga pada jam-jam tertentu terjadi kemacetan. Untuk mendukung kehidupan perkotaan yang nyaman dan asri, tentunya kehadiran ruang terbuka hijau tak dapat dipisahkan dari suatu perencanaan sebuah kota.

Ruang terbuka hijau yang terdapat di Kota Pontianak salah satunya adalah lanskap jalan. Lanskap jalan adalah wajah dari karakter lahan atau tapak yang terbentuk pada lingkungan jalan, baik yang terbentuk dari elemen lanskap alam seperti bentuk topografi lahan maupun yang terbentuk dari elemen lanskap buatan manusia yang disesuaikan dengan kondisi lahannya (Direktorat Jenderal Bina Marga, 1996). Kehadiran tanaman pada jalur hijau memiliki nilai estetika yang dapat memperbaiki dan meningkatkan kualitas visual jalan.

Penataan diperlukan untuk mewujudkan lanskap jalan yang kualitas. Hal ini menuntut pemilihan tanaman dan pola penataan yang fungsional dan estetis. Namun untuk 
mengetahui apakah penerapannya sudah memenuhi syarat fungsi, estetika dan pemeliharaan lanskap, diperlukan suatu studi evaluasi lanskap jalan yang dapat dijadikan pedoman dalam menciptakan suatu lanskap yang fungsional dan estetik. Evaluasi lanskap jalan diperlukan untuk mengoptimalkan efektivitas tanaman pada jalur hijau jalan dalam mewujudkan konsep jalan dalam kota yang memberi kelancaran, keselamatan dan peningkatan kualitas lingkungan serta visual jalan.

Tujuan penelitian ini adalah untuk (1) evaluasi fungsional dari aspek arsitektural, estetika dan pemeliharaan lanskap Jalan Jenderal Ahmad Yani dan (2) memberikan rekomendasi yang tepat dalam pengelolaan lanskap jalan Kota Pontianak.

\section{Metode}

Lokasi penelitian di Jalan Jenderal Ahmad Yani Pontianak. Panjang jalan mencapai 5 $\mathrm{km}$ yang dibagi menjadi 3 segmen yaitu: 1. Perempatan Ahmad Yani - pertigaan Jalan Veteran, 2. Pertigaan Jalan Ahmad Yani - Veteran sampai Bundaran Untan, dan 3. Bundaran Untan - perempatan Jalan Ahmad Yani (depan Polda).

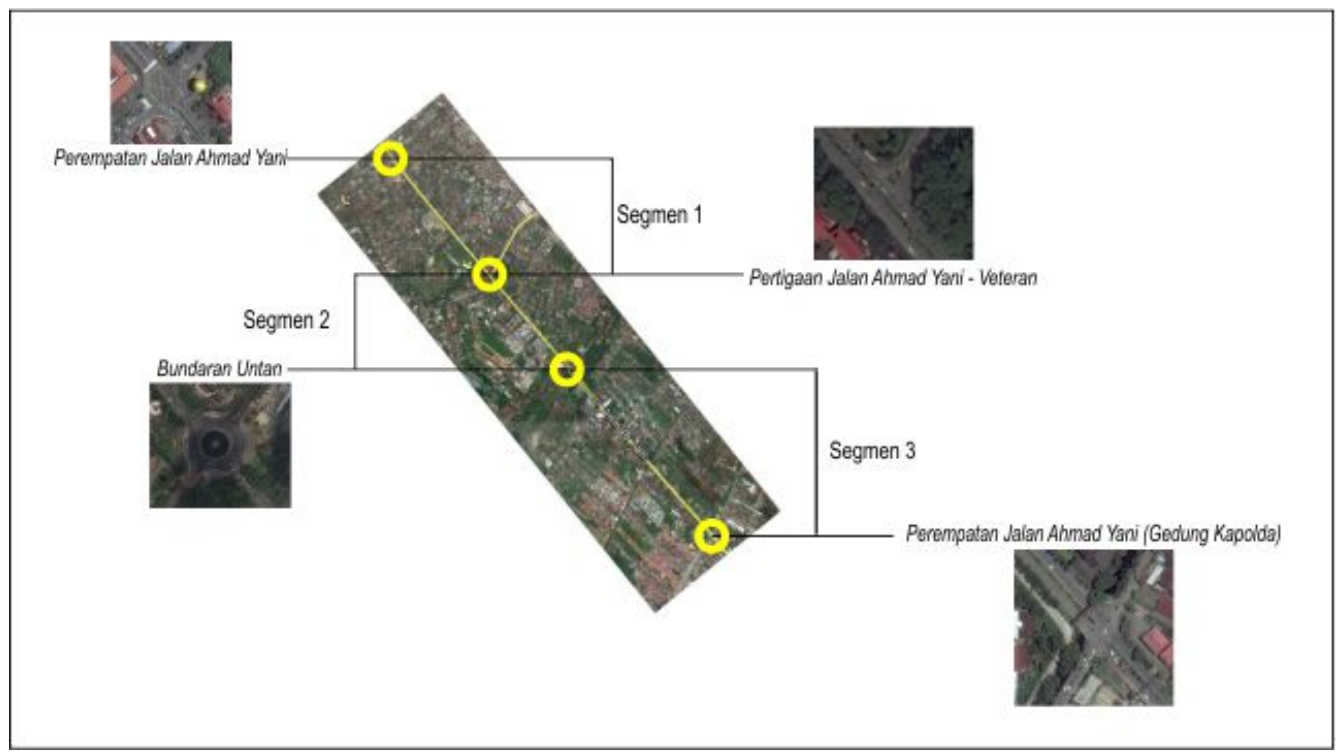

Gambar 1. Lokasi Penelitian

Metode penelitian menggunakan metode survei. Pelaksanaan penelitian dilakukan dengan tahapan: (1) studi literatur yang terkait dengan lingkup penelitian, (2) inventarisasi, dan (3) analisis data meliputi penilaian dengan menggunakan kriteria yang sudah teruji. Data yang sudah diperoleh kemudian dianalisis dengan melakukan penilaian masingmasing aspek arsitektural, aspek estetika dan aspek pemeliharaannya. Data dianalisis secara deskriptif maupun kuantitatif dengan membandingkan data yang diperoleh dengan standar dan dasar penilaian untuk kriteria-kriteria yang ditetapkan. Kriteria tersebut disusun berdasarkan standar yang diperoleh dari berbagai literatur, hasil kriteria disajikan pada Tabel 1. 
Tabel 1. Kriteria dan Penilaian Arsitektural, Estetika dan Pemeliharaan Tanaman

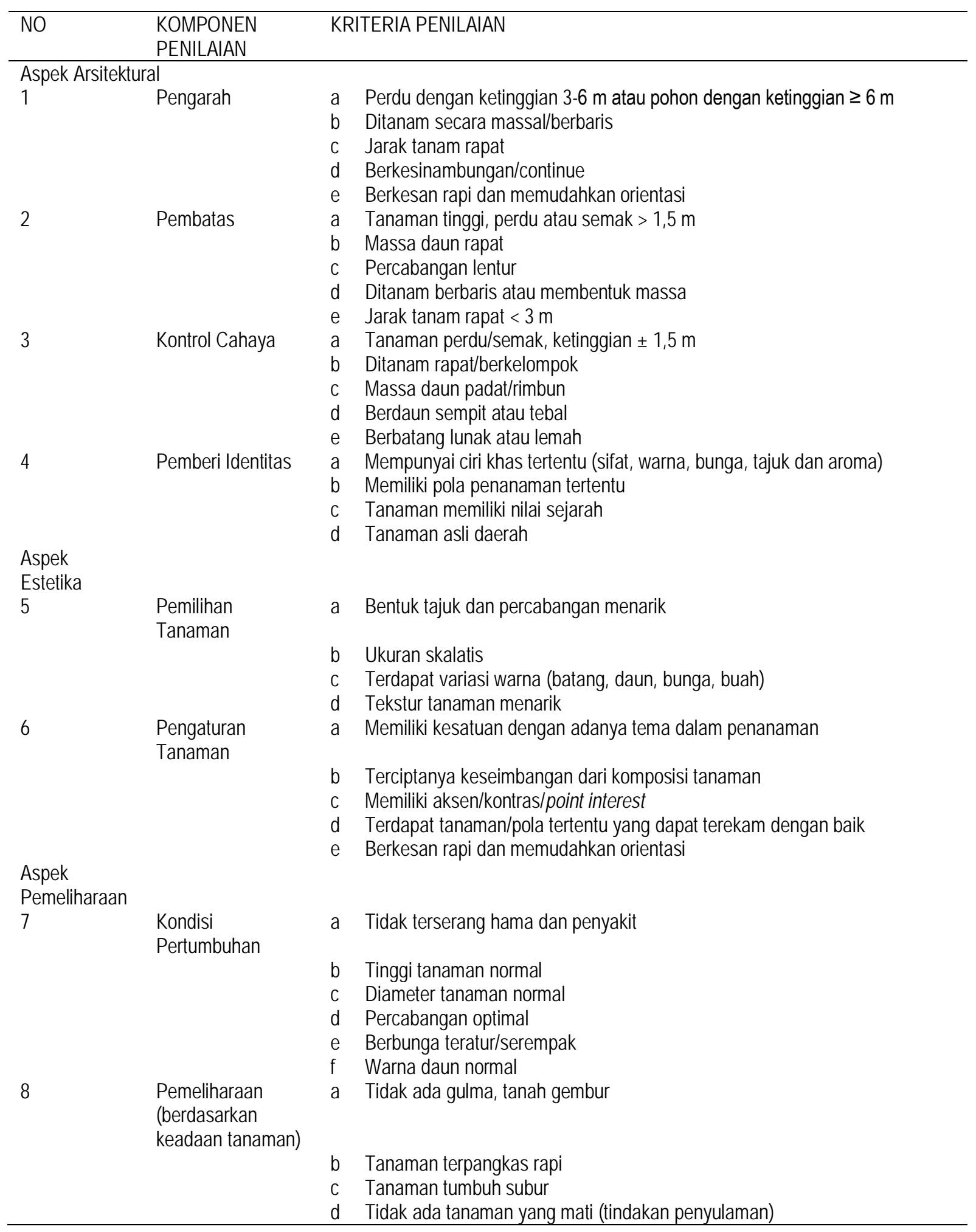

Penilaian dilakukan dengan pembobotan kriteria dengan memberikan nilai 1-3. Secara umum nilai 1 merupakan nilai buruk, nilai 2 merupakan nilai cukup dan nilai 3 
merupakan nilai baik. Tiap komponen penilaian memiliki batas angka yang berbeda. Tabel 2 menyajikan batas nilai untuk tiap komponen.

Tabel 2. Komponen Nilai dan Batas Penilaian

\begin{tabular}{|c|c|c|c|c|c|c|c|}
\hline \multirow{2}{*}{$\begin{array}{l}\text { Komponen } \\
\text { Penilaian }\end{array}$} & \multirow{2}{*}{$\begin{array}{l}\text { Jumlah } \\
\text { Kriteria }\end{array}$} & \multicolumn{3}{|c|}{ Nilai } & \multicolumn{3}{|c|}{ Batas Nilai } \\
\hline & & Min & Maks & Interval & 1 & 2 & 3 \\
\hline $\begin{array}{l}\text { Aspek } \\
\text { Arsitektural }\end{array}$ & 19 & 19 & 57 & 13 & $\begin{array}{c}\leq 32 \\
\text { (tidak sesuai) }\end{array}$ & $\begin{array}{c}\text { 33-34 } \\
\text { (kurang sesuai) }\end{array}$ & $\begin{array}{c}\geq 45 \\
\text { (sesuai) }\end{array}$ \\
\hline Aspek Estetika & 9 & 9 & 27 & 6 & $\begin{array}{l}\leq 15 \\
\text { (buruk) }\end{array}$ & $\begin{array}{l}16-21 \\
\text { (cukup) }\end{array}$ & $\begin{array}{l}\geq 22 \\
\text { (baik) }\end{array}$ \\
\hline $\begin{array}{l}\text { Aspek } \\
\text { Pemeliharaan }\end{array}$ & 10 & 10 & 30 & 7 & $\begin{array}{l}\leq 17 \\
\text { (buruk) }\end{array}$ & $\begin{array}{l}18-24 \\
\text { (cukup) }\end{array}$ & $\begin{array}{l}\geq 25 \\
\text { (baik) }\end{array}$ \\
\hline Kumulatif & 38 & 38 & 114 & 25 & $\begin{array}{l}\leq 63 \\
\text { (buruk) }\end{array}$ & $\begin{array}{l}64-89 \\
\text { (cukup) }\end{array}$ & $\begin{array}{l}\geq 90 \\
\text { (baik) }\end{array}$ \\
\hline
\end{tabular}

\section{Hasil dan Pembahasan}

\subsection{Hasil}

Parameter yang diamati pada lanskap Jalan Jenderal Ahmad Yani Pontianak adalah aspek arsitektural, aspek estetika dan aspek pemeliharaan. Rangkuman hasil penilaian pada masing-masing aspek dapat dilihat pada Tabel 3.

Tabel 3. Rangkuman Hasil Penilaian Aspek Rekayasa Dan Arsitektural, Aspek Estetika Dan Aspek Pemeliharaan Jalan Ahmad Yani

\begin{tabular}{lccc}
\hline \multirow{2}{*}{ Lokasi } & \multicolumn{3}{c}{ Nilai } \\
\cline { 2 - 4 } Segmen 1 & Aspek Arsitektural & Aspek Estetika & Aspek Pemeliharaan \\
& 34 & 17 & 26 \\
Segmen 2 & (kurang sesuai) & (cukup) & (baik) \\
& 36 & 14 & 27 \\
Segmen 3 & (sesuai) & (buruk) & (baik) \\
& 36 & 17 & 26 \\
& (sesuai) & (cukup) & (baik) \\
\hline
\end{tabular}

Hasil menunjukkan bahwa segmen 2 dan 3 memenuhi kriteria aspek arsitektural. Aspek estetika untuk segmen 2 dan 3 dinilai cukup memenuhi kecuali segmen 3 , sedangkan untuk aspek pemeliharaan diketahui bahwa ketiga segmen memenuhi kriteria baik.

Booth (1983) mengelompokkan fungsi vegetasi dl lingkungan perkotaan kedalam tiga fungsi utama yaitu fungsi struktural, fungsi lingkungan dan fungsi visual. Fungsi struktural meliputi fungsi tanaman sebagai dinding, atap dan lantai dalam membentuk suatu ruang serta mempengaruhi pemandangan dan arah pergerakan. Fungsi lingkungan meliputi peran tanaman dalam meningkatkan kualitas udara dan kualitas air, mencegah erosi serta peran tanaman dalam memodifikasi iklim. Fungsi visual merupakan peran tanaman sebagai titik yang dominan dan sebagai penghubung visual melalui karakteristik yang dimilikinya yaitu ukuran, bentuk, warna dan tekstur. 


\subsection{Pembahasan}

Aspek Arsitektural

Kegunaan arsitektural unsur tanaman sangat penting dalam penataan lanskap terutama sebagai pembentuk ruang luar. Dalam pengembangan perancangan, kegunaan arsitektural adalah yang pertama dipelajari. Karakteristik visual unsur tanaman umumnya dipilih setelah fungsi arsitekturalnya ditetapkan. Unsur tanaman digunakan secara arsitektural dalam fungsi lanskap sebagai komponen struktural seperti lantai, atap, dan dinding. Secara arsitektural tanaman merupakan ruang kegiatan pada ruang luar.

Komponen penilaian aspek arsitektural didominansi oleh fungsi tanaman sebagai pengarah, diikuti oleh pembatas, kontrol cahaya dan pemberi identitas. Ketiga segmen memiliki vegetasi pepohonan yang berjajar rapi membentuk barisan yang berfungsi sebagai pengarah. Masa daun yang padat dan penanaman yang rapat. Nilai tertinggi pada segmen 2, di sana terdapat barisan glodokan tiang yang rapi.
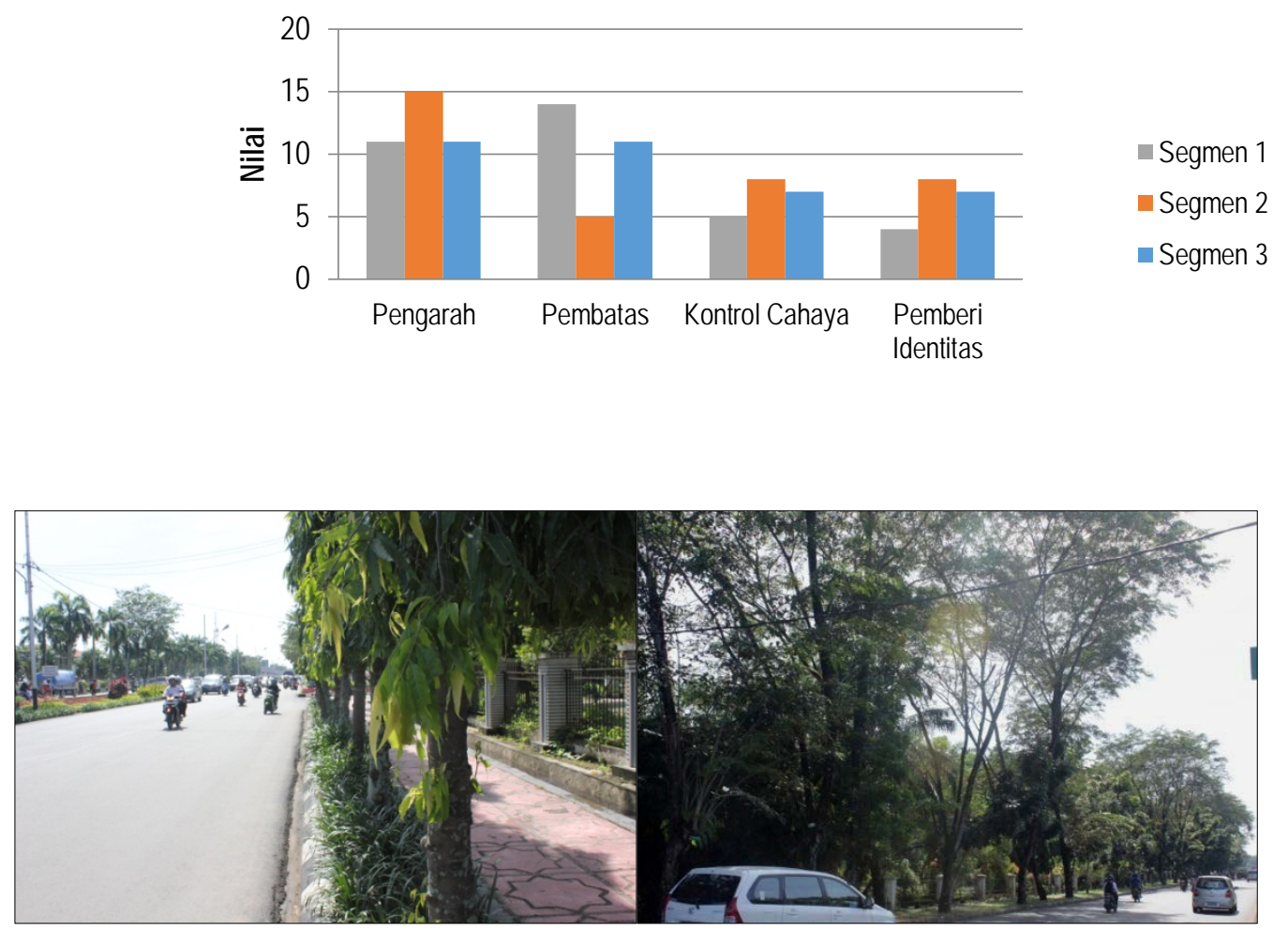

Gambar 3. Fungsi Pengarah Pada A) Segmen 2, B) Segmen 3 


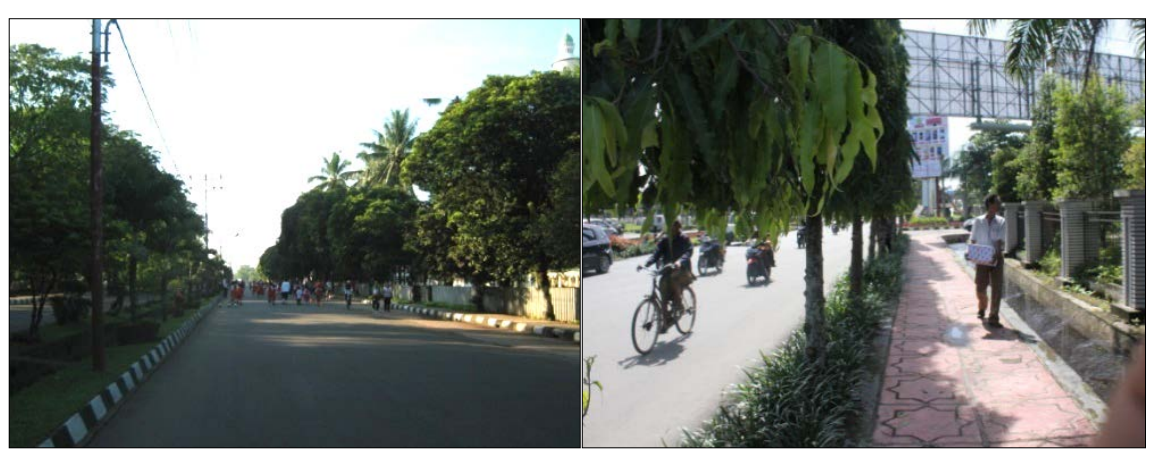

Gambar 4. Fungsi Kontrol Cahaya A) Segmen 1, B) Segmen 2

Sebagian besar tanaman pada ke tiga segmen tersebut bermassa daun padat, bertekstur kasar, memiliki daun yang sempit dan tidak mudah rontok, dan memiliki percabangan yang lentur. Kondisi tersebut harus ditingkatkan melalui penanaman tanaman yang berbaris, berkesinambungan, dan merata hampir di seluruh segmen jalan. Selain itu, penanaman juga harus dikomposisikan dengan baik untuk mendapatkan kesan visual yang kuat sesuai dengan kondisi sosial dan lingkungan lanskap jalan pada masingmasing segmen.

\section{Aspek Estetika}

Unsur tanaman selain berfungsi untuk kegunaan arsitektural dalam perancangan, yaitu untuk membentuk ruang, menciptakan urut-urutan ruang, menghalangi pandangan, membentuk ruang keleluasaan pribadi, juga memiliki kegunaan estetika. Kegunaan arsitektural lebih ditekankan pada aspek struktural, sedangkan kegunaan estetika lebih menyangkut pada kualitas visual suatu perancangan.

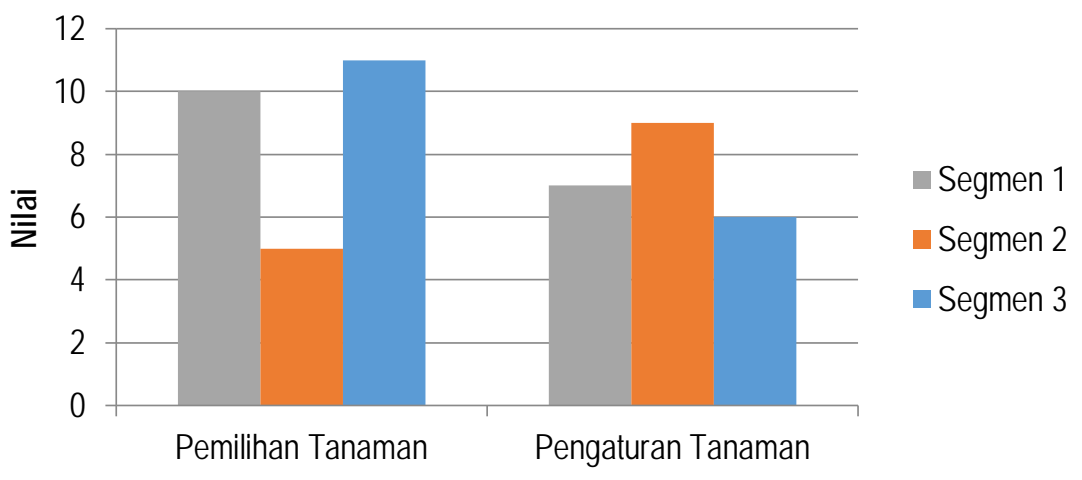

Gambar 4. Grafik Nilai Estetika

Pemilihan jenis tanaman, segmen 2 memiliki nilai terendah karena pada lokasi tersebut jenis pepohonan yang dipilih memiliki tajuk dan cabang yang sederhana dan seragam. Tidak terdapat variasi warna yang menarik. Sedangkan untuk pengaturan tanaman sudah tertata dengan rapi.

Kehadiran tanaman pada jalur hijau memiliki nilai estetika yang dapat memperbaiki dan meningkatkan kualitas visual jalan. Kualitas visual jalan raya yang baik dapat 
diperoleh dengan menggunakan tanaman yang mempunyai bentuk arsitektur yang serasi dengan lingkungannya. Dengan keindahan bentuk arsitekturnya, pengadaan tanamantanaman tersebut sekaligus dapat menghiasi wajah perkotaan.

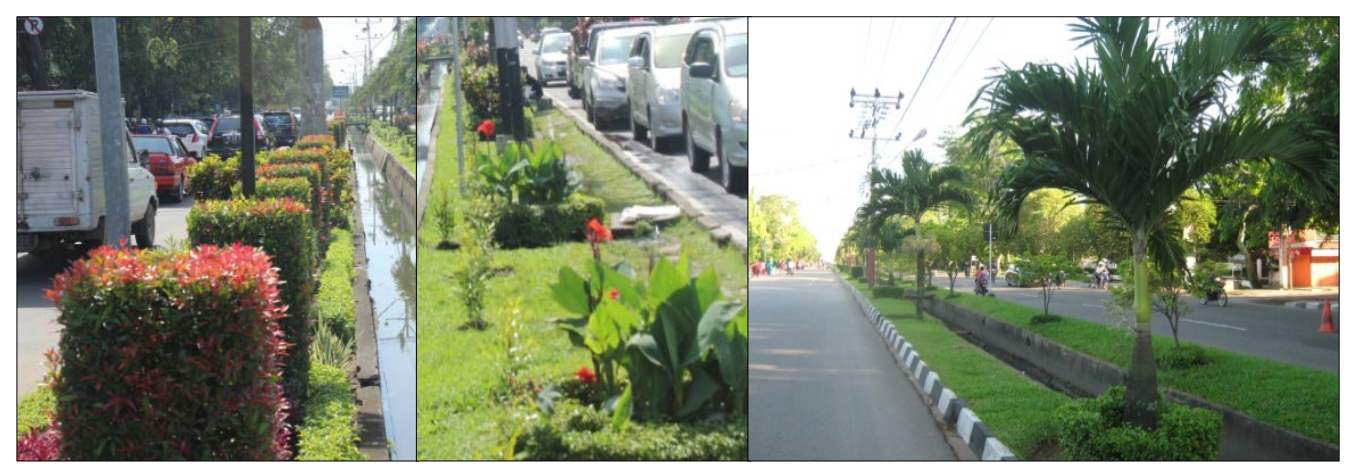

Gambar 5. Fungsi Estetika Pada Penataan Tanaman

Selanjutnya Simonds (1983) menjelaskan bahwa suatu jalan harus memberi kesan yang menyenangkan dari setiap pergerakan, dimana akan berguna dan menyenangkan bagi pemakai jalan jika terdapat keharmonisan dan kesatuan dengan karakteristik lanskap yang ada sehingga fungsional secara fisik dan visual.

Ukuran, bentuk, warna, dan tekstur tanaman serta susunan komposisi dan hubungannya dengan lingkungan sekitar merupakan faktor-faktor yang mempengaruhi kualitas estetika suatu perancangan. Kualitas visual dalam penataan tanaman sangat penting, karena tanggapan seseorang merupakan reaksi terhadap apa yang terlihat. Suatu penataan tanaman dapat berfungsi dengan baik sebagai pembentuk ruang, memodifikasi suhu udara, menstabilkan tanah, tetapi apabila kurang menarik akan mengganggu pandangan. Penataan tanaman yang berhasil, apabila dapat menarik pandangan, disamping menyempurnakan fungsi-fungsi yang lain.

Tanaman pada lanskap jalan raya memiliki peran yang cukup besar. Carpenter, et. al. (1975) mengemukakan bahwa kehadiran tanaman di lingkungan perkotaan memberikan suasana alami. Daun-daun hijau tanaman dengan berbagai tekstur dan bayangan yang ditimbulkan oleh pohon menghadirkan kelembutan serta kesegaran pada areal beraspal. Tanaman juga dapat menetralkan suasana tertekan akibat temperatur tinggi, polusi udara serta suasana bising. Jalur hijau tepi jalan dapat dijadikan suatu tempat rekreasi dan berolahraga bagi masyarakat kota. Suasana rutin dan sibuk yang terlihat setiap hari di perkotaan dapat berubah menjadi lebih santai dengan keindahan dan kenyamanan yang dihadirkan oleh tanaman di jalur hijau.

\section{Aspek Pemeliharaan Lanskap}

Keberadaan tanaman yang berfungsi optimal sedikit banyak ditentukan oleh pemeliharaan yang baik. Pemeliharaan lanskap dimaksudkan untuk menjaga dan merawat areal lanskap dengan segala fasilitas yang ada di dalamnya agar kondisinya tetap baik 
atau sedapat mungkin mempertahankan pada keadaan yang sesuai dengan tujuan rancangan atau disain semula (Arifin dan Nurhayati, 1995).

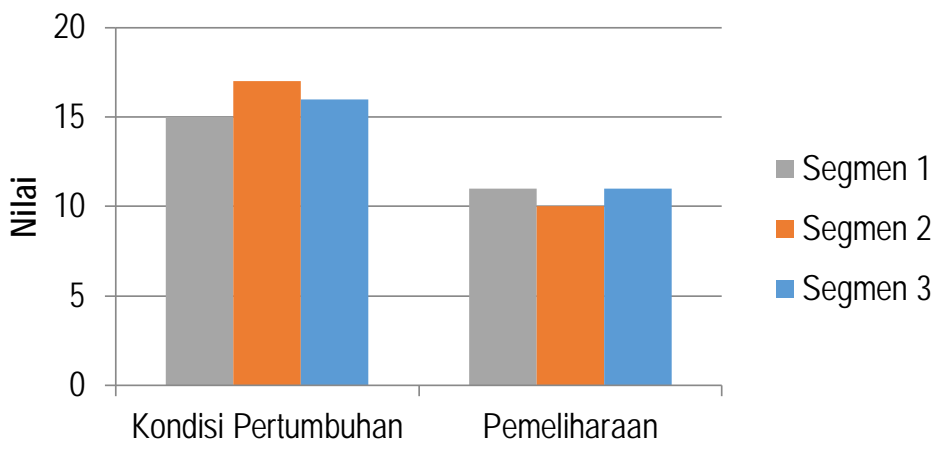

Gambar 6. Grafik Nilai Pemeliharaan Lanskap

Hasil pengamatan menunjukkan bahwa semua lokasi telah memenuhi kriteria pemeliharaan, hal dapat dilihat dengan kondisi tanaman yang terawat dan rapi. Menurut Rachman (1984) di dalam pemeliharaan lanskap dikenal istilah pemeliharaan ideal dan pemeliharaan fisik. Pemeliharaan ideal merupakan pemeliharaan yang mengacu pada tujuan dan disain semula, karenanya pada periode waktu tertentu diadakan suatu evaluasi. Pemeliharaan fisik meliputi pekerjaan untuk tetap menjaga keindahan, keasrian, kenyamanan dan keamanan lanskap. Pekerjaan tersebut mencakup kegiatan penyiraman tanaman, pembersihan, pendagiran, penyiangan gulma, pemangkasan, penyulaman, pemupukan, pengendalian hama dan penyakit dan pengangkutan sampah.

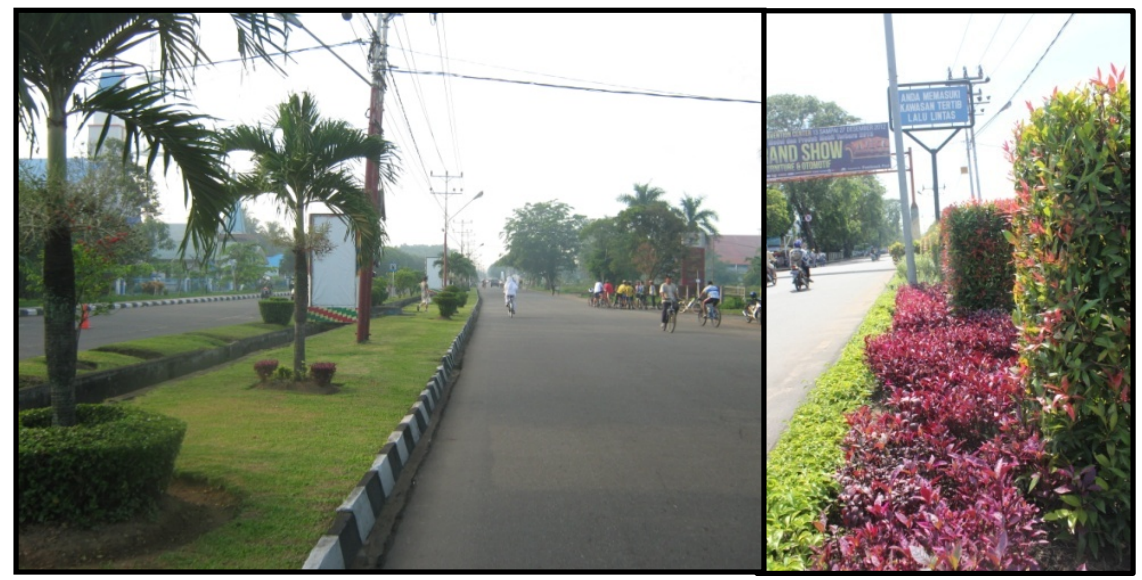

Gambar 7. Tanaman Yang Terawat Rapi

Adapun tujuan dari perencanaan dan pengelolaan tata hijau jalan adalah 1)untuk keselamatan pengguna jalan yang dicapai dengan timbulnya pengaruh psikologis dari adanya tata ruang yang terbentuk karena penghijauan dan pengindahan. Pengaruh ini dirancang agar dapat membimbing, mengarahkan dan memberi tanda-tanda lintasan, memberikan kesegaran perasaan, menambah konsentrasi kearah depan dan berguna dalam mengurangi pengaruh angin yang dapat menganggu stabilitas kendaraan. 2) 
Kenyamanan dan kenikmatan pengguna jalan dalam perjalanan. 3) Pengembangan tapak pelestarian bagi flora dan fauna.

Cara yang dapat dilakukan untuk meningkatkan nilai pemeliharaan adalah: (1) Penataan dengan pola sederhana secara alami untuk menghemat biaya pemeliharaan, (2) Agar tanaman dapat tumbuh dan beradaptasi dengan baik harus diperhatikan persyaratan tumbuh tanaman, (3) Pemilihan tanaman sebaiknya tidak menggunakan tanaman-tanaman yang pemeliharaannya sulit atau tinggi, dan (4) Perlu dilakukan upaya pemeliharaan yang intensif mulai dari penyiraman, penyulaman, pemangkasan, pendagiran, pemupukan dan pengendalian hama dan penyakit tanaman.

\section{Simpulan}

Kriteria aspek arsitektural dipenuhi di segmen 2 dan 3, aspek estetika untuk segmen 2 dan 3 dinilai cukup memenuhi kecuali segmen 3, sedangkan untuk aspek pemeliharaan diketahui bahwa ketiga segmen memenuhi kriteria baik.

\section{Daftar Pustaka}

Arifin, H.S. dan Nurhayati. 1999. Pemeliharaan Taman. Penebar Swadaya. Jakarta.

Booth, N. K. 1983. Basic Elements Of Landscape Architectural Design. Waveland Press. Illinois.

Carpenter, P.L., T.D. Walker and F.O. Lanphear. 1975. Plants in the Landscape. W.H. Freeman and Company. New York.

Direktorat Jenderal Bina Marga. 1996. Tata Cara Perencanaan Teknik Lanskap Jalan. Departemen Pekerjaan Umum. Jakarta.

Ecbo, G. 1956. The Art of Home Landscaping. Mc Graw Hill Inc. New York.

Rachman, Z. 1984. Pertamanan sebagai IImu dan Seni Pencipta Lingkungan Indah dan Berguna (Tidak dipublikasikan). Makalah Ceramah Bogor Flora Festival, Bogor.

Simonds, J.O. 1983. Landscape Architecture. Mc.Graw-Hill, Inc. United States of America. 